Article

\title{
Effect of the Incorporation of Titanium on the Optical Properties of ZnO Thin Films: From Doping to Mixed Oxide Formation
}

\author{
Miriam Yuste ${ }^{1}$, Ramon Escobar-Galindo ${ }^{1,2}{ }^{\oplus}$, Noelia Benito ${ }^{3,4}$, Carlos Palacio ${ }^{4}$, \\ Oscar Martínez ${ }^{5}$, Jose Maria Albella ${ }^{1}$ and Olga Sánchez ${ }^{1, *(\mathbb{D})}$ \\ 1 Instituto de Ciencia de Materiales de Madrid (CSIC), 28049 Madrid, Spain; \\ miriam_yuste@hotmail.com (M.Y.); ramon.escobar@uca.es (R.E.-G.); jmalbella@icmm.csic.es (J.M.A.) \\ 2 Departamento de Ciencia de los Materiales e Ingeniería Metalúrgica y Química Inorgánica, IMEYMAT, \\ Universidad de Cádiz, 11510 Puerto Real, Spain \\ 3 Dept. de Física, Universidad de Concepción, Casilla 160-C, Concepción 4030000, Chile; \\ noelia.benito@ing.uchile.cl \\ 4 Dept. de Física Aplicada, Universidad Autónoma de Madrid, 28049 Madrid, Spain; carlos.palacio@uam.es \\ 5 UGdS-Optronlab Group, Dpto. Física Materia Condensada, Universidad de Valladolid, Paseo de Belén 11, \\ 47011 Valladolid, Spain; oscar@fmc.uva.es \\ * Correspondence: olgas@icmm.csic.es
}

Received: 17 January 2019; Accepted: 5 March 2019; Published: 8 March 2019

check for updates

\begin{abstract}
ZnO}$ films with Ti atoms incorporated (TZO) in a wide range (0-18 at.\%) have been grown by reactive co-sputtering on silicon and glass substrates. The influence of the titanium incorporation in the $\mathrm{ZnO}$ matrix on the structural and optical characteristics of the samples has been determined by Rutherford backscattering spectroscopy (RBS), X-ray photoelectron spectroscopy (XPS) and X-ray diffraction (XRD). The results indicate that the samples with low Ti content $(<4$ at.\%) exhibit a wurtzite-like structure, with the $\mathrm{Ti}^{4+}$ ions substitutionally incorporated into the $\mathrm{ZnO}$ structure, forming Ti-doped $\mathrm{ZnO}$ films. In particular, a very low concentration of $\mathrm{Ti}(<0.9$ at.\%) leads to a significant increase of the crystallinity of the TZO samples. Higher Ti contents give rise to a progressive amorphization of the wurtzite-like structure, so samples with high Ti content $(\geq 18$ at.\%) display an amorphous structure, indicating in the XPS analysis, a predominance of $\mathrm{Ti}-\mathrm{O}-\mathrm{Zn}$ mixed oxides. The energy gap obtained from absorption spectrophotometry increases from $3.2 \mathrm{eV}$ for pure $\mathrm{ZnO}$ films to $3.6 \mathrm{eV}$ for those with the highest Ti content. Ti incorporation in the $\mathrm{ZnO}$ samples $<0.9$ at. $\%$ raises both the blue $(380 \mathrm{~nm}$ ) and green (approx. $550 \mathrm{~nm}$ ) bands of the photoluminescence (PL) emission, thereby indicating a significant improvement of the PL efficiency of the samples.
\end{abstract}

Keywords: Ti doped ZnO; thin film; co-sputtering; UV-visible

\section{Introduction}

Zinc oxide $(\mathrm{ZnO})$ is a semiconductor material characterized by a broadband gap (approx. $3.2-3.3 \mathrm{eV}$ ), a high transmission in the visible spectral range, a native n-type conductivity as well as by its excellent photoluminescence (PL) properties, which can be modified by the incorporation of impurities in its structure [1,2]. The PL emission of $\mathrm{ZnO}$ films presents essentially two peaks, in the $\mathrm{UV}$ and in the visible spectrum, at approximately $380 \mathrm{~nm}$ and in the $450-730 \mathrm{~nm}$ range, respectively. It is well-known that the degree of crystallinity of the films has a strong influence on the UV emission efficiency [3,4]. On the other hand, inherent defects in the material, such as zinc $(\mathrm{Zn})$ or oxygen $(\mathrm{O})$ interstitials or vacancies controlled by the method and growth conditions, determine the presence of PL emissions in the visible range [2]. 
A subject that currently interests numerous researchers is the improvement of the optical and electrical behaviour of $\mathrm{ZnO}$ films with the incorporation of metals in its structure (Al, Ga, In, Ti, etc.), demanded from the point of view of new potential applications: transparent conductive contacts (TCOs), laser diodes including UV light emitting diodes, thin film transistors, mobile phones, microwave dielectrics, etc. [5-8]. Actually, n-type doping controlled by the incorporation of certain elements in the $\mathrm{ZnO}$ network is a recurrent method for tailoring both the bandwidth energy and electrical conductivity by increasing the concentration of carriers while keeping a high transparency in the visible range [9]. Most of previous work on doped $\mathrm{ZnO}$ films is related to doping with group III elements (Al, Ga and In), while most recently, new studies have been conducted on quadrivalent dopants like titanium, which can provide two free electrons per atom to improve the conductivity of the $\mathrm{ZnO}$ host and to modify the photoresponse.

Furthermore, $\mathrm{ZnO}$ ceramic materials with a high Ti content have also been searched because of their applications in paint pigments, gas sensors, catalytic sorbents for removal of contaminants from hot coal gases $\left(\mathrm{H}_{2} \mathrm{~S}\right.$, As, etc.), photocatalytic splitting of water and degradation of organic compounds, as well as in anodes of Li-ion batteries, microwave devices and low-temperature co-fired ceramics $[10,11]$.

For these reasons, the study of $\mathrm{ZnO}$ films with $\mathrm{Ti}$ atoms incorporated and the understanding of the Ti incorporation into the $\mathrm{ZnO}$ structure, either as dopant or in the form of a mixed oxide, are still under debate and constitute a very interesting challenge. To obtain Ti-incorporated $\mathrm{ZnO}(\mathrm{TZO})$ thin films, sputtering techniques have been reported in the literature [12-14]. However, in most of the reports concerning sputtering techniques, $\mathrm{RF}$ magnetron sputtering and $\mathrm{ZnO}$ targets [13] or ZnO:Ti targets [14] were used. In the present project, we propose the deposition of ZnO:Ti thin films in a wide range of Ti atomic concentrations by the means of the reactive DC magnetron co-sputtering technique and by using two separate targets of pure $\mathrm{Ti}$ and $\mathrm{Zn}$ and no intentional heating. We already used this approach in a previous work [12] for ultrathin films, and due to the excellent results, in terms of the range of \%Ti that was incorporated in the films, we have applied the same methodology here. In our work [12], our group explored the structural phase and composition of TZO ultrathin films $(<40 \mathrm{~nm})$ using X-ray absorption spectroscopy (XANES) and Rutherford Backscattering Spectroscopy (RBS). TZO films with an increasing Ti content show a gradual transition from the typical tetrahedral coordination for titanium atoms at lower contents $(<3$ at.\%) to the octahedral coordination for higher contents (up to 22 at.\%) with a hexagonal $\mathrm{ZnTiO}_{3}$-like structure.

In order to further investigate the effect of Ti addition on the properties of sputtered $\mathrm{ZnO}$ films, we present, in this work, the structural and optical characterization of thicker TZO films (approx. $200 \mathrm{~nm}$ ) and their evolution with the titanium content. The crystalline structure determined by low angle X-ray diffraction, observing how the highly oriented deposits grown with a preferential (002) direction of the original $\mathrm{w}-\mathrm{ZnO}$ structure, is affected by the incorporation of titanium. The composition of the films has been obtained from RBS, while the oxidation state of incorporated Ti atoms to the $\mathrm{ZnO}$ structure has been examined by X-ray photoelectron spectroscopy (XPS). The surface morphology of the samples has been observed by scanning electron microscopy (SEM). In addition, the variation in the optical properties (transmittance and optical band gap) with the Ti content has been measured by ultraviolet-visible (UV-Vis) spectrophotometry, observing an improvement in the transparency at low wavelengths when titanium is substitutionally incorporated in the $\mathrm{ZnO}$ lattice. The presence of defects (excitons) has been also analysed by photoluminescence (PL) measurements.

\section{Materials and Methods}

TZO films have been deposited on both (100)-oriented silicon samples (resistivity $>6000 \Omega \cdot \mathrm{cm}$ ) and Corning glass slides, by reactive magnetron co-sputtering in an argon atmosphere with $20 \%$ oxygen and a total constant gas flow of $30 \mathrm{sccm}$. Two independent cathodes (Ti and $\mathrm{Zn}$ ) fed with different DC power were used to control the Ti/Zn relative content in the films. All the samples were prepared after the complete poisoning of both cathodes. No intentional heating was applied during 
deposition, though the measured substrate temperature was approx. $90^{\circ} \mathrm{C}$. Table 1 shows the power applied in the $\mathrm{Zn}$ and Ti cathode sources $\left(P_{Z n}\right.$ and $P_{T i}$, respectively). The deposition time was adjusted to obtain in all samples a thickness of $200 \mathrm{~nm}$ except in the sample deposited at the lowest $P_{Z n}$ power ( $\mathrm{Zn} / \mathrm{Ti}-10 / 100)$ due to the low sputtering rate of Ti (approx. 4 times lower than $\mathrm{Zn}$ ). The thickness of the layers was determined by profilometry (Veeco, model Dektak 150, Plainview, NY, USA).

Table 1. The deposition conditions, composition and density of the samples. The error in the composition was estimated at $1 \%$.

\begin{tabular}{|c|c|c|c|c|c|c|c|}
\hline \multirow{2}{*}{ Sample } & \multirow{2}{*}{$P_{Z n}(\mathrm{~W})$} & \multirow{2}{*}{$P_{T i}(W)$} & \multirow{2}{*}{$\begin{array}{c}\text { Thickness } \\
\text { (nm) }\end{array}$} & \multicolumn{3}{|c|}{ Composition (at.\%) } & \multirow{2}{*}{$\begin{array}{l}\text { Density } \\
\left(\mathrm{g} / \mathrm{cm}^{3}\right)\end{array}$} \\
\hline & & & & Ti & $\mathrm{Zn}$ & O & \\
\hline $\mathrm{ZnO}$ & 100 & 0 & $199 \pm 5$ & - & 48 & 52 & 5.6 \\
\hline $\mathrm{Zn} / \mathrm{Ti}-100 / 10$ & 100 & 10 & $197 \pm 5$ & 0.2 & 45.9 & 53.9 & 4.6 \\
\hline $\mathrm{Zn} / \mathrm{Ti}-100 / 60$ & 100 & 60 & $200 \pm 9$ & 0.9 & 44.9 & 54.3 & 4.5 \\
\hline $\mathrm{Zn} / \mathrm{Ti}-100 / 100$ & 100 & 100 & $200 \pm 7$ & 1.2 & 43.5 & 55.3 & 4.2 \\
\hline Zn/Ti-60/100 & 60 & 100 & $207 \pm 3$ & 4.1 & 40.8 & 55.1 & 4.8 \\
\hline $\mathrm{Zn} / \mathrm{Ti}-10 / 100$ & 10 & 100 & $57 \pm 2$ & 18.2 & 17.7 & 64.1 & 3.6 \\
\hline $\mathrm{TiO}_{2}$ & 0 & 100 & $18 \pm 2$ & 30.8 & - & 69.2 & 3.8 \\
\hline
\end{tabular}

The chemical composition of the films was obtained by RBS with the 5 MV HVEE Tandetron accelerator at the Autonomous University of Madrid. These experiments were performed using $\mathrm{He}^{+}$ ions of $3.035 \mathrm{MeV}$, corresponding to the resonance of oxygen atoms and thus improving the oxygen atoms sensitivity. The chemical composition values have been extracted using the RBX software [15].

The crystalline structure of the TZO films with different Ti contents was identified by X-ray diffraction with the Bragg-Brentano configuration (Siemens D 5000, Berlin, Germany, with Cu anode, $\mathrm{K} \alpha$ radiation $=1.54178 \AA)$. A low incidence angle $\left(0.7^{\circ}\right)$ was used to obtain the preferred orientation of the crystals.

An XPS analysis were carried out in an ultrahigh vacuum system (residual pressure approx. $8 \times 10^{-8} \mathrm{~Pa}$ ) equipped with a hemispheric analyser (SPECS Phoibos $100 \mathrm{MCD}-5$, Berlin, Germany) The pass energy was $9 \mathrm{eV}$, giving a constant resolution of $0.9 \mathrm{eV}$. A twin anode (Al-Mg) X-ray source was operated at a constant power of $300 \mathrm{~W}$, using the $\mathrm{Mg} \mathrm{K \alpha}(1253.6 \mathrm{eV})$ radiation. The Au $4 f_{7 / 2}$, $\mathrm{Ag} 3 d_{5 / 2}$ and $\mathrm{Cu} 2 p_{3 / 2}$ lines at 84.0, 368.3 and $932.7 \mathrm{eV}$, respectively, of the reference samples were chosen for the calibration of the binding energy (BE). The possible charging effects produced during XPS measurements were corrected using as reference the BE of the $\mathrm{C} 1 \mathrm{~s}$ peak $(285 \mathrm{eV})$ due to the adventitious $\mathrm{C}$.

The optical characteristics (transmittance) and energy gap, $E_{g}$, have been obtained from optical spectrophotometry in the wavelength range from 300 to $2000 \mathrm{~nm}$ using a SolidSpec-3700 spectrophotometer (Shimadzu Corp., Kyoto, Japan). In order to assess the effect of Ti addition in the ZnO matrix, PL measurements were also carried out using a Labram system, model HR800 UV, provided with a He-Cd laser $(325 \mathrm{~nm})$ and a diffraction grating of 150 lines $/ \mathrm{mm}$ with $40 \times$ lenses.

SEM images of the surface morphology of $\mathrm{ZnO}$ films with different Ti contents were obtained with a Philips XL30 SFEG system (Amsterdam, The Netherlands).

\section{Results and Discussion}

\subsection{Film Composition and RBS Analysis}

Figure 1 shows both the experimental and the fitted RBS spectra of the series of TZO samples, including pure $\mathrm{ZnO}$ and $\mathrm{TiO}_{2}$ reference films. A zoom $(\times 20)$ of the energy zone between 2000 and $2500 \mathrm{keV}$ is also attached to the spectra to better observe the metal signal. An excellent fitting of the experimental spectra was obtained by assuming a single layer of $\mathrm{Zn}-\mathrm{Ti}-\mathrm{O}$ on the silicon substrate. The results indicate a good quality of the substrate-film interface (within an estimated resolution 
about $5 \mathrm{~nm}$ ), thus confirming that the composition of the layer is very homogeneous throughout the whole thickness.

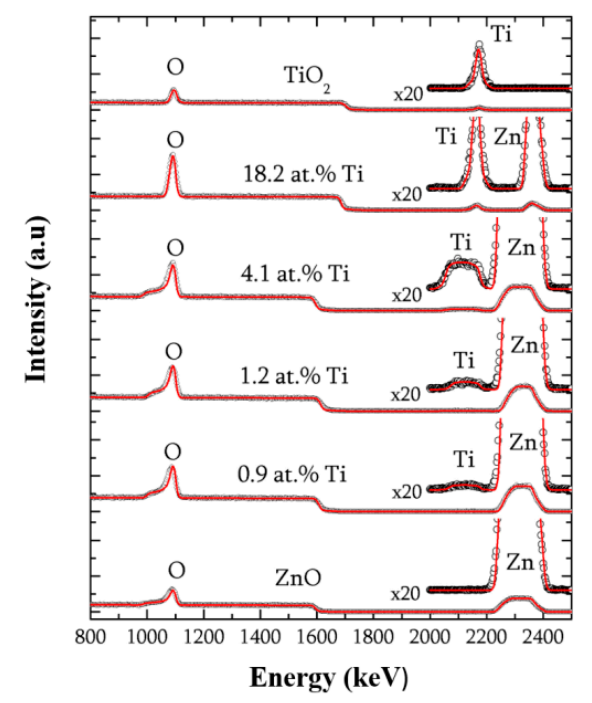

Figure 1. The Rutherford backscattering spectroscopy (RBS) spectra (experimental and simulated) of $\mathrm{ZnO}$ films with an increasing Ti content (from below to above): A zoom $(\times 20)$ is included for the high energy region to magnify the signal of $\mathrm{Zn}$ and $\mathrm{Ti}$.

The density of the films (Table 1) was calculated from the RBS curves using the film thicknesses obtained by profilometry. It decreases as the Ti incorporation increases from the reference value for $\mathrm{ZnO}\left(5.6 \mathrm{~g} / \mathrm{cm}^{3}\right)$ to the density of the pure $\mathrm{TiO}_{2}$ sample $\left(3.8 \mathrm{~g} / \mathrm{cm}^{3}\right)$. This is a consequence of the lower atomic mass of $\mathrm{Ti}(22 \mathrm{amu})$ as compared to $\mathrm{Zn}(30 \mathrm{amu})$, as far as the titanium is incorporated substitutionally in the $\mathrm{ZnO}$ structure, as discussed below.

Figure 2 gives the variation of the composition of the TZO films as a function of the power applied to one of the cathodes (either $\mathrm{Zn}$ or Ti), keeping constant the other at $100 \mathrm{~W}$. According to the data in Table 1, in the samples deposited with a fixed power in the Ti cathode, $P_{\mathrm{Ti}}=100 \mathrm{~W}$, the Ti content decreases abruptly from 30.8 at.\% (pure $\mathrm{TiO}_{2}$ ) to 1.2 at.\% as the power in the $\mathrm{Zn}$ source is increased. Conversely, in the samples deposited with a constant power of the $\mathrm{Zn}$ cathode, $P_{\mathrm{Zn}}=100 \mathrm{~W}$, the Ti content takes lower values from 0 (pure $\mathrm{ZnO}$ sample) to 1.2 at.\%. Apart from the other factors, this effect is a consequence of the larger sputtering yield of $\mathrm{Zn}$ as compared with that of Ti. Thus, the use of two independent sputtering sources allows a wide range of compositions in the TZO films to be obtained.

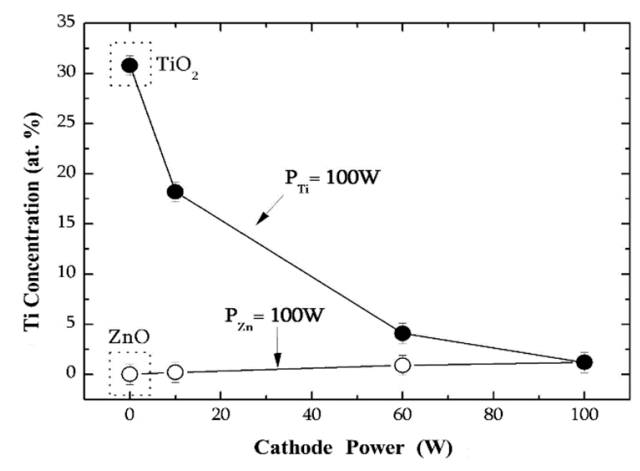

Figure 2. A variation of the Ti concentration in the films as a function of the applied power to the cathodes ( $\mathrm{Zn}$ and $\mathrm{Ti}$ ) for a fixed power of Ti (upper curve) and $\mathrm{Zn}$ (lower curve), respectively. 


\subsection{Crystalline Structure}

Figure 3 shows the X-ray spectra obtained for the samples disclosed in Table 1 . As can be observed, a pure $\mathrm{ZnO}$ sample grown as a reference presents the typical polycrystalline hexagonal wurtzite structure with a (002) preferential orientation. The samples deposited with the lowest power applied to the Ti cathode $(10 \mathrm{~W})$, resulting in a Ti concentration of 0.2 at.\%, show a peak centred in the position corresponding to the plane (002) of the $\mathrm{ZnO}$ but with much higher intensity than that obtained for the reference $\mathrm{ZnO}$ sample (note that the intensity of the spectrum is divided by a factor of 3). In addition, no $\mathrm{TiO}_{2}$ peaks were detected. These results indicate that the $\mathrm{Ti}$ atoms are incorporated as a dopant (electron donor) in the wurtzite structure, substituting the zinc atoms in the $\mathrm{ZnO}$ lattice and significantly improving the crystallinity of the doped $\mathrm{ZnO}$ sample. This interpretation is consistent with the smaller radius of $\mathrm{Ti}^{4+}(0.068 \mathrm{~nm})$ as compared to the $\mathrm{Zn}^{2+}$ radius $(0.074 \mathrm{~nm})[7,16]$.

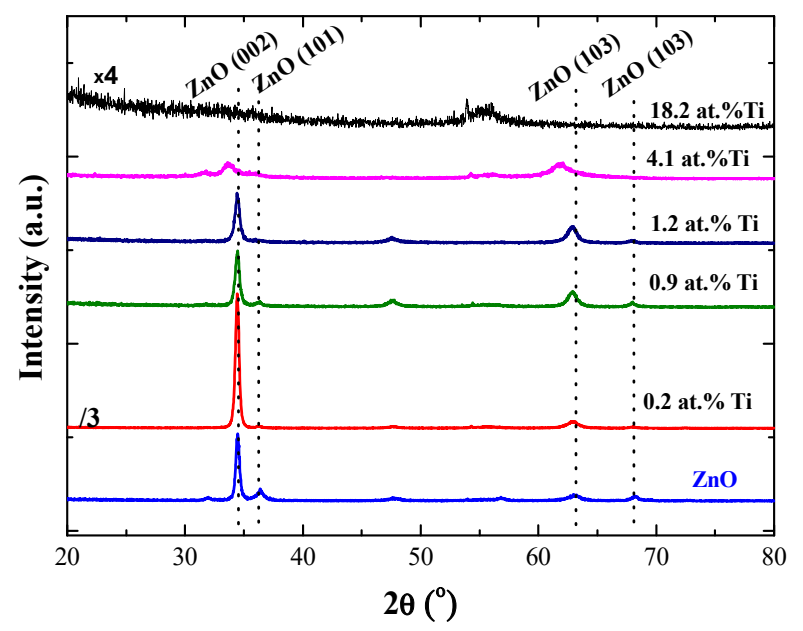

Figure 3. The X-ray spectra of Ti-incorporated $\mathrm{ZnO}(\mathrm{TZO})$ films with different Ti content. (Notice that the intensity of the sample with a Ti content at 0.2 at.\% is divided by 3 , whereas the sample with 18.2 at.\% $\mathrm{Ti}$ is multiplied by 4 .).

However, when the titanium concentration increases above 1.2 at.\%, the intensity of the (002) peak decreases and widens, suggesting a progressive amorphization of the sample [16]. This is more apparent in the TZO samples with 4.1 at.\% Ti, where the $\mathrm{ZnO}$ peaks suffer a shift towards lower diffraction angles. This fact has been explained by the compressive stress generated in the direction parallel to the surface, which induces an increase in the interplanar spacing, eventually leading to the peak displacement at lower angles, as detected in Figure $3[16,17]$. However, the presence of some zinc titanate crystallites cannot be discarded [18].

The loss of crystallinity when the amount of Ti atoms increases above a certain level has also been interpreted as a result of the intense flux of sputtered Ti atoms on the sample surface during the film growth [17]. Thus, the film with the highest Ti concentration (18.2 at.\%) is completely amorphous, not showing any crystalline planes associated with $\mathrm{ZnO}$. However, these amorphous samples could keep a certain atomic bonding structure with an octahedral coordination typical of titanate phases (ilmenite), as we previously reported in Caretti et al. [12] for ultrathin TZO samples ( $<40 \mathrm{~nm})$ with a high Ti content (>18 at.\%).

\subsection{XPS Analysis}

XPS measurements were performed on selected TZO films to obtain a qualitative analysis of the chemical oxidation state of the elements in the compound. Figure 4 depicts detailed windows for the $\mathrm{Zn} 2 p_{3 / 2}$, O $1 s$ and Ti $2 p$ levels of the analysed samples: pure $\mathrm{ZnO}$ and $\mathrm{TiO}_{2}$ reference films, along with samples with low (0.9 at.\%) and high Ti contents ( $\geq 18$ at.\%). As can be observed in Figure 4a, the $\mathrm{Zn} 2 p_{3 / 2}$ spectrum of the $\mathrm{ZnO}$ films displays a peak at $1022.5 \mathrm{eV}$ (vertical dotted line) characteristic 
for $\mathrm{ZnO}$ bonds, which slightly shifts (approx. $0.2 \mathrm{eV}$ ) to the high $\mathrm{BE}$ side once Ti is detected in the network, implying that the nature of the link between $\mathrm{Zn}$ and $\mathrm{O}$ atoms has been slightly modified.

Similarly, Figure 4 b shows the Ti $2 p$ doublet for the $\mathrm{TiO}_{2}$ reference film (upper part) with a main peak at $459.1 \mathrm{eV}$ and a spin-orbit splitting of approx. $5.7 \mathrm{eV}$ that can be attributed to Ti-O bonds [19]. Those peaks shift approx. $0.2 \mathrm{eV}$ to the high BE side with decreasing Ti contents in the films. In addition, the signals of Ti for the TZO samples are detected with a very low intensity for both levels, $2 p_{3 / 2}$ and $2 p_{1 / 2}$, characteristic of the doublet $\mathrm{TiO}_{2}$.

As for the $\mathrm{O} 1 \mathrm{~s}$ peak of the $\mathrm{ZnO}$ reference film, Figure 4c displays a main peak at $531.2 \mathrm{eV}$ that can be attributed to $\mathrm{Zn}-\mathrm{O}$ bonds and a shoulder at approx. $1.6 \mathrm{eV}$ above the main peak that has been attributed to oxygen-defect sites related to oxygen vacancies in the matrix [18]. It is worth noting that the shoulder disappears and that the main peak shifts to $530.6 \mathrm{eV}$ with increasing Ti contents. The gradual shift of the Ti $2 p$ doublet to the high BE side and the fact that the $\mathrm{O} 1 \mathrm{~s} \mathrm{BE}$ is somewhere between those of $\mathrm{TiO}_{2}$ and $\mathrm{ZnO}$ indicates that $\mathrm{Ti}-\mathrm{O}$ bonds are more ionic than in pure $\mathrm{TiO}_{2}$, pointing to the formation of Ti-O-Zn mixed oxides instead of the formation of single oxide phases as reported before for the Ti-O-Si system [20,21].
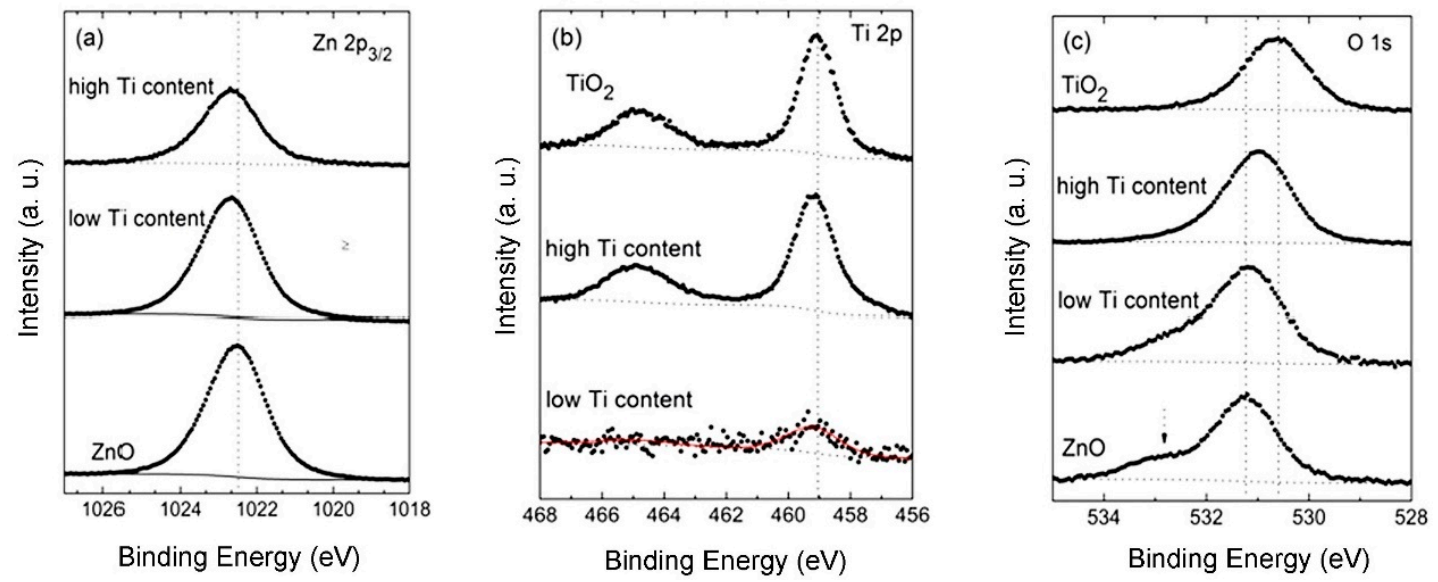

Figure 4. Spectra of Zn $2 p$ (a), Ti $2 p$ (b) and O 1 s (c) of the TZO films with low (approx. 0.9 at.\%) and high ( $\geq 18$ at.\%) Ti content, including the reference $\mathrm{ZnO}$ and $\mathrm{TiO}_{2}$ samples: The vertical dotted lines represent the position of the reference energy of the $\mathrm{ZnO}(\mathbf{a}), \mathrm{TiO}_{2}(\mathbf{b})$, and $\mathrm{O}-\mathrm{Zn}$ and $\mathrm{O}-\mathrm{Ti}(\mathbf{c})$ chemical bonds.

\subsection{SEM Observations}

Figure 5a shows the SEM image of the surface of as-deposited pure $\mathrm{ZnO}$ films, made of inhomogeneous polycrystalline grains, according to the XRD results (Figure 3). The incorporation of a small amount of $\mathrm{Ti}(0.2$ at.\%) in the $\mathrm{ZnO}$ structure (Figure $5 \mathrm{~b}$ ) does not produce significant differences in the morphology of the sample with respect to the initial $\mathrm{ZnO}$ films, though the distribution of grains is more homogeneous all over the surface. This confirms that the low doping of $\mathrm{ZnO}$ induces the film growth with more aligned and ordered crystalline structures than that of pure $\mathrm{ZnO}$ films. As the concentration of $\mathrm{Ti}$ in the sample increases (4.1 at.\%), seen in Figure $5 c$, the grain size decreases and, most notably, in the case of films with 18.2 at.\% of Ti (Figure $5 \mathrm{~d}$ ), where the grain boundaries are barely appreciated. The surface morphology in these high Ti coatings is close to that of those observed in as-deposited $\mathrm{TiO}_{2}$ films (Figure 5e) that are fully amorphous [22,23], which is in agreement to the findings of Mullerova et al. [18]. 

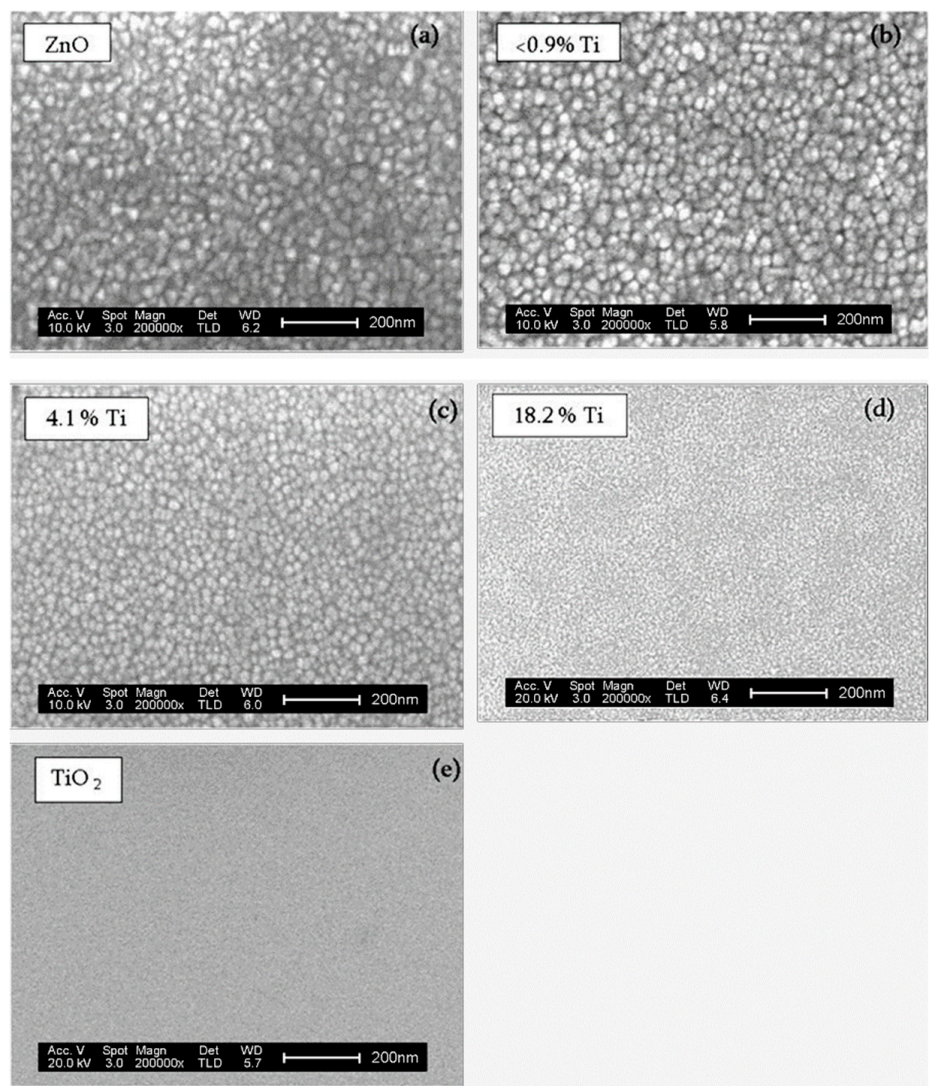

Figure 5. SEM images of the surface of the $\mathrm{ZnO}$ samples with different contents of $\mathrm{Ti}(\mathbf{b}-\mathbf{d})$, including the reference samples of $\mathrm{ZnO}(\mathbf{a})$ and $\mathrm{TiO}_{2}(\mathbf{e})$.

Summarizing these observations, along with the structure and composition data obtained by RBS, XRD, XPS and SEM, including previous XANES results [12], one can classify the sputtered TZO coatings in three compositional groups with different properties:

- Films with a low Ti content ( $<0.9$ at. $\%)$, exhibit a highly crystalline wurtzite-like structure, where the $\mathrm{Ti}^{4+}$ ions are incorporated into the $\mathrm{ZnO}$ structure by substituting the $\mathrm{Zn}$ atoms, thus forming crystalline Ti-doped $\mathrm{ZnO}$ films.

- TZO films with a medium Ti content (up to 4.1 at.\%) show a wurtzite structure which becomes amorphous with increasing Ti content.

- $\quad$ TZO films with a high Ti content (18.2 at.\%) display a fully amorphous structure with a predominance of the Ti-O-Zn oxides (probably ilmenite type) and a minor content of wurtzite.

\subsection{Optical Properties}

Figure 6 shows the transmittance spectra obtained for the TZO samples with different Ti contents. We also included the spectrum of a stoichiometric $\mathrm{ZnO}$ film. As can be observed, the samples present a high transparency (approx. 80\%) in the wavelength range 400-800 nm, except for the layers with a high Ti concentration (18.2 at.\%), which the transmittance of is significantly lower. As stated above, this sample shows an amorphous structure, made of a mixture of Ti-O-Zn oxides of a very small column size. According to some authors, the presence of Ti-O aggregates in these films might reduce the transmission of light in the visible range as a consequence of the light scattering losses associated to a high density of grain boundaries [16]. Diffuse transmittance experiments would be needed to confirm this hypothesis. However, such experiments are beyond the scope of this work. In any case, the absorption edge of samples with a Ti content of $\leq 4.1 \%$ is shifted to lower wavelengths for increasing Ti concentrations, as seen in the Figure 6. 


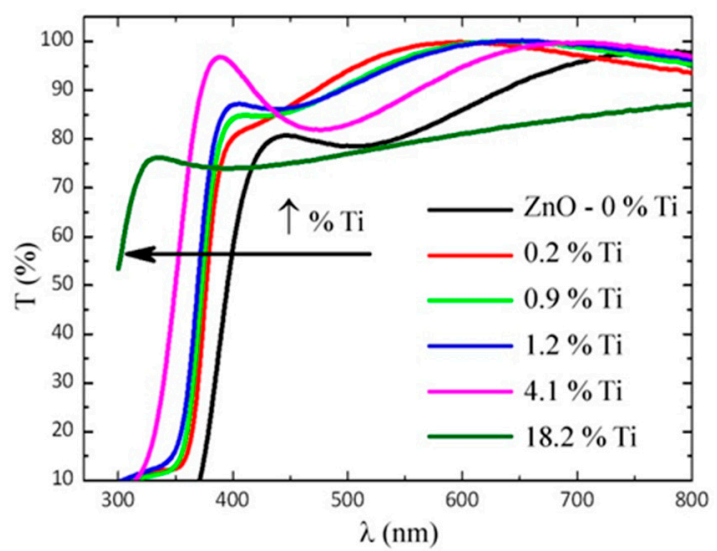

Figure 6. The optical transmittance spectra of TZO samples with different Ti contents, including the $\mathrm{ZnO}$ reference film: The arrow indicates the direction in which the optical absorption edge shifts when the Ti content increases.

From the above results, the optical behaviour has been analysed in more detail in terms of the calculated absorption coefficient, $\alpha$, of the samples. An adequate fitting of the $(\alpha h v)^{n}$ values with $n=1 / 2$ or 2 allows one to identify the type of electronic transitions across the bandgap (either indirect or direct, respectively) in the light absorption process. Figure 7 depicts the $(\alpha h v)^{2}$ values (Tauc plot) corresponding to the best fit of the above alternatives, i.e., direct transitions of the TZO films. From these curves, it is possible to obtain the energy gap by extrapolation of the asymptote in the high-energy range to the energy axis. The evolution of the $E_{g}$ with the titanium concentration in the TZO films is displayed in Figure 8.

As it can be appreciated, the gap energy increases monotonously from $3.2 \mathrm{eV}$ for pure $\mathrm{ZnO}$ to 3.3 $\mathrm{eV}$ for low Ti-doped films with the wurtzite structure. This increase can be interpreted in terms of the Moss-Burstein model, which states that a virtual shift of the band gap for highly doped degenerate semiconductors $[24,25]$. In this case, the large electronic population in the conduction band leads to a displacement of the Fermi level above the bottom of the conduction band so that the excited electrons need a larger energy to jump to the Fermi level (i.e., the highest occupied levels).

As stated above, for a larger Ti content in the films, the wurtzite-like structure progressively becomes more amorphous and the gap rises up to $3.6 \mathrm{eV}$ when the Ti content is $4.1 \mathrm{at} . \%$. Finally, in a highly doped film (Ti concentration is 18.2 at.\%) the bandwidth increases to $3.9 \mathrm{eV}$. In this case, this value cannot be justified by the doping effect, but instead, it could have arisen by the presence of a different amorphous TZO compound.

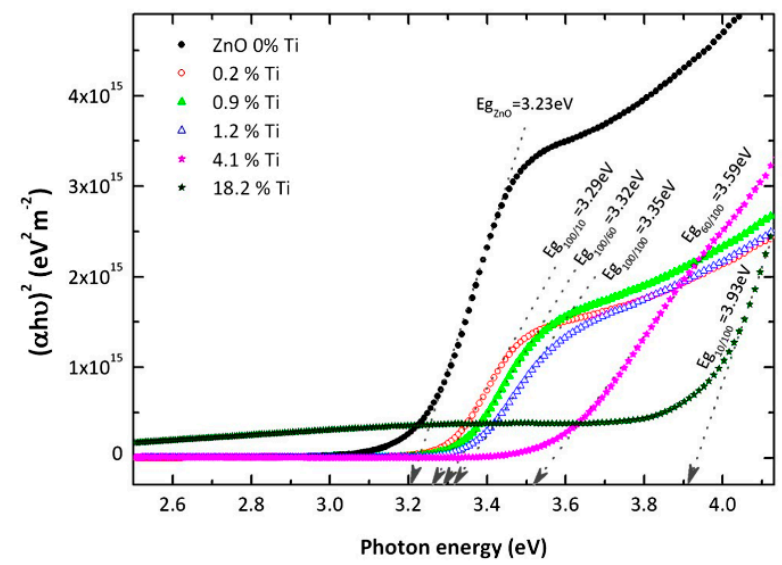

Figure 7. The variation in the $(\alpha h v)^{2}$ values as a function of energy for $\mathrm{ZnO}$ films with different concentrations of Ti incorporation (from 0 to 18.2 at.\%). 


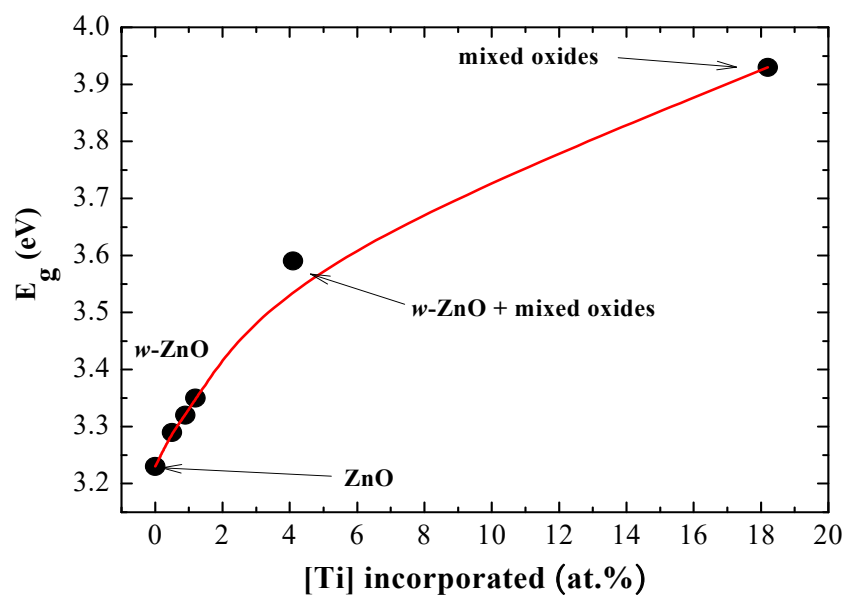

Figure 8. The energy gap, $E_{\mathrm{g}}$, for TZO films as a function of the incorporated Ti content (the solid line is drawn as a guide for the eye).

\subsection{Photoluminescence (PL)}

Figure 9 illustrates the PL spectra of selected TZO samples. A reference spectrum of stoichiometric $\mathrm{ZnO}$ is included as well. The pure $\mathrm{ZnO}$ films exhibit a PL peak in the UV region $(380 \mathrm{~nm})$ attributed to the near band edge excitation of defects, as well as a wide green band (approx. $550 \mathrm{~nm}$ ) of lower intensity due to shallow defects $[7,26]$. The incorporation of $\mathrm{Ti}(0.2$ at.\%) in the $\mathrm{ZnO}$ films raises both PL signals, increasing the intensity of the blue band in a factor of 2 and thereby indicating a significant increase in PL efficiency in the UV range, which corroborates the improvement of the crystallinity of low-doped $\mathrm{ZnO}$ films as detected by XRD. This behaviour is explained by the increase of exciton defects caused by the substitution of the $\mathrm{Zn}^{2+}$ by $\mathrm{Ti}^{4+}$ ions in $\mathrm{ZnO}$ lattice [7,27].

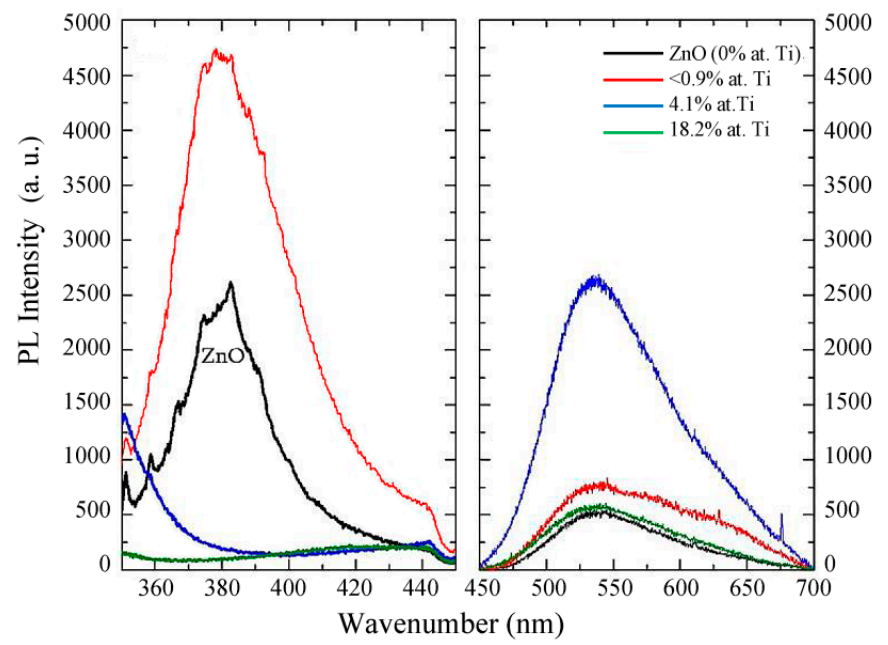

Figure 9. Photoluminescence (PL) spectra of the TZO samples with different Ti contents.

For higher Ti concentrations in the film structure (4.1 at.\% and 18.2 at.\%), the PL spectra show, in both cases, a tail at wavelengths above $360 \mathrm{~nm}$, suggesting the presence of the corresponding emission peaks, likely of low intensity, deeper in the blue range (out of the detection limit of the spectrophotometer). As aforementioned, these samples correspond either to a mixture of crystalline $\mathrm{ZnO}$ and other amorphous compounds (for $\mathrm{Ti}=4.1$ at.\%) or to the amorphous titanate phase (for $\mathrm{Ti}=18.2$ at.\%). Indeed, the optical energy band gaps for these materials are 3.6 and $3.9 \mathrm{eV}$, respectively (Figure 8), which may give rise to near edge excitonic transitions in that region.

Generally, the green band of the PL spectra of TZO films is attributed to single ionized oxygen vacancies $[2,24,27]$, in agreement to our XPS results (see above). The large emission intensity observed 
for the sample with 4.1 at.\% Ti corroborates the existence of $\mathrm{w}-\mathrm{ZnO}$ aggregates within the titanate phase, which is supposed to bear a large defect concentration. On the other hand, the decrease of the emission in this optical range for the sample with a much higher Ti content (18.2 at.\%) can be associated to the amorphous nature of pure titanate films, which present a broad low emission band in the 500-600 nm range, as observed in Figure 9. This phenomenon has been related to the presence of delocalized electronic levels (Ti- $\mathrm{O}_{5}$ clusters) in the optical bandgap [28]. As it is well-known, amorphous semiconductors have a large population of electronic states close to the band edges (mobility gap) which obviously may smooth the PL spectra of the green band. Nevertheless, the green luminescence processes in $\mathrm{ZnO}$ materials are still a matter of intense debate [1].

\section{Conclusions}

The above results demonstrate a close relationship between the crystalline structure of sputtered TZO coatings and their optical response, determined by the atomic Ti concentration in the films. Specifically, films with a low Ti content $(\leq 0.9$ at.\%) exhibit a highly crystalline wurtzite-like structure, with the $\mathrm{Ti}^{4+}$ ions substitutionally incorporated into the $\mathrm{ZnO}$ structure, forming Ti-doped $\mathrm{ZnO}$ films. Their energy gap ( $3.3 \mathrm{eV}$ ) is slightly higher than in reference $\mathrm{ZnO}$ films $(3.2 \mathrm{eV})$. Higher Ti contents still keep the wurtzite structure, which becomes progressively amorphous with increasing Ti content, widening the energy gap. At Ti concentration of 18.2 at.\%, the material displays a fully amorphous structure of Ti-O-Zn mixed oxides and the gap further increases to $3.9 \mathrm{eV}$. On the other hand, the PL characteristics of pure $\mathrm{ZnO}$ films show the typical blue band (which the position of correlates with optical gap), as well as the green band, associated to the near edge excitation of defects, likely ionized oxygen vacancies. Ti addition below 0.9 at.\% in the films raises the UV band emission, thereby indicating a significant improvement of PL efficiency. For larger Ti contents (4.1 at.\%), there is a shift of the blue band to the deep UV range, whereas the green band increases likely due to a larger defect concentration in the band gap. Finally, the amorphous nature of the films for Ti at 18.2 at.\% preserves a similar PL emission (blue and green band), both with much lower intensity. Hence, we prove that there is a very narrow window of titanium content to be incorporated into the structure of $\mathrm{ZnO}$ films to improve its crystalline structure as well as its luminescence and other optical properties.

Author Contributions: Conceptualization, R.E.-G. and O.S.; Methodology, R.E.-G and O.S.; Formal Analysis, R.E.-G. and O.S. and M.Y.; Investigation, M.Y., N.B. and O.M.; Writing-Original Draft Preparation, J.M.A. and O.S.; Writing-Review and Editing, O.S., C.P., R.E.-G. and J.M.A.

Funding: We acknowledge financial support from the Comunidad Autónoma de Madrid under project DIMMAT ref: CAM S2013/MIT-2775 and from the Spanish government under the project MAT2015-68892-R.

Acknowledgments: We acknowledge Javier Ortiz for his technical support.

Conflicts of Interest: The authors declare no conflict of interest.

\section{References}

1. Rodnyi, P.A.; Khodyuk, I.V. Optical and luminescence properties of zinc oxide. Opt. Spectrosc. 2011, 111, 776-785. [CrossRef]

2. Özgür, Ü.; Alivov Ya, I.; Liu, C.; Teke, A.; Reshchikov, M.A.; Doğan, S.; Avrutin, V.; Cho, S.-J.; Morkoç, H. A comprehensive review of $\mathrm{ZnO}$ materials and devices. Appl. Phys. Lett. 2005, 98, 041301. [CrossRef]

3. Bang, K.H.; Hwang, D.K.; Myoung, J.M. Effects of $\mathrm{ZnO}$ buffer layer thickness on properties of $\mathrm{ZnO}$ thin films deposited by RF magnetron sputtering. Appl. Surf. Sci. 2003, 207, 359-364. [CrossRef]

4. Ohara, S.; Mousavanda, T.; Umetsua, M.; Takamia, S.; Adschiri, T.; Kuroki, Y.; Takata, M. Hydrothermal synthesis of fine zinc oxide particles under supercritical conditions. Solid State Ion. 2004, 172, 261-264. [CrossRef]

5. Anders, A.; Lim, S.H.N.; Yu, K.M.; Andersson, J.; Rosén, J.; McFarland, M.; Brown, J. High quality ZnO:Al transparent conducting oxide films synthesized by pulsed filtered cathodic arc deposition. Thin Solid Films 2010, 518, 3313-3319. [CrossRef] 
6. Cornelius, S.; Vinnichenko, M.; Shevchenko, N.; Rogozin, A.; Kolitsch, A.; Möllerless, W. Achieving high free electron mobility in $\mathrm{ZnO}: \mathrm{Al}$ thin films grown by reactive pulsed magnetron sputtering. Appl. Phys. Lett. 2009, 94, 042103. [CrossRef]

7. Chen, H.; Guo, W.; Ding, J.; Ma, S. Ti-incorporated ZnO films synthesized via magnetron sputtering and its optical properties. Superlattices Microstruct. 2012, 51, 544-551. [CrossRef]

8. Jain, P.K.; Salim, M.; Kaur, D. Effect of phase transformation on optical and dielectric properties of pulsed laser deposited $\mathrm{ZnTiO}_{3}$ thin films. Superlattices Microstruct. 2016, 92, 308-315. [CrossRef]

9. Irimpan, L.; Krishnan, B.; Nampoori, V.P.N.; Radhakrishnan, P. Luminescence tuning and enhanced nonlinear optical propertiesof nanocomposites of $\mathrm{ZnO}-\mathrm{TiO}_{2}$. J. Colloid Interface Sci. 2008, 324, 99-104. [CrossRef]

10. Jose, M.; Elakiya, M.; Dhas, S.A.M.B. Structural and optical properties of nanosized $\mathrm{ZnO} / \mathrm{ZnTiO}_{3}$ composite materials synthesized by a facile hydrothermaltechnique. J. Mater. Sci. Mater. Electron. 2017, 28, 13649-13658. [CrossRef]

11. Lee, Y.C.; Huang, Y.L.; Lee, W.H.; Shieu, F.S. Formation and transformation of $\mathrm{ZnTiO}_{3}$ prepared by sputtering process. Thin Solid Films 2010, 518, 7366-7371. [CrossRef]

12. Caretti, I.; Yuste, M.; Torres, R.; Sánchez, O.; Jiménez, I.; Galindo, R.E. Coordination chemistry of titanium and zinc in $\mathrm{Ti}_{(1-x)} \mathrm{Zn}_{2 x} \mathrm{O}_{2}(0 \leq x \leq 1)$ ultrathin films grown by DC reactive magnetron sputtering. RSC Adv. 2012, 2, 2696-2699. [CrossRef]

13. Yu, W.; Han, D.; Li, H.; Dong, J.; Zhou, X.; Yi, Z.; Luo, Z.; Zhanga, S.; Zhang, X.; Wang, Y. Titanium doped zinc oxide thin film transistors fabricated by cosputtering technique. Appl. Surf. Sci. 2018, 459, 345-348. [CrossRef]

14. Kumar, M.; Singh, J.P.; Chae, K.H.; Kim, J.H.; Lee, H.H. Structure, optical and electronic structure studies of Ti:ZnO thin films. J. Alloy. Compd. 2018, 759, 8-13. [CrossRef]

15. Kòtai, E. Computer methods for analysis and simulation of RBS and ERDA spectra. Nucl. Instrum. Methods Phys. Res. B 1994, 85, 588-596. [CrossRef]

16. Zhao, Z.W.; Zhou, Q.; Zhang, X.; Wu, X. A study on Ti-doped ZnO transparent conducting thin films fabricated by pulsed laser deposition. Appl. Surf. Sci. 2014, 305, 481-486. [CrossRef]

17. Lu, J.J.; Lu, Y.M.; Tasi, S.I.; Hsiung, T.L.; Wang, H.P.; Jang, L.Y. Conductivity enhancement and semiconductor-metal transitionin Ti-doped ZnO films. Opt. Mater. 2017, 29, 1548-1552. [CrossRef]

18. Mullerová, J.; Sutta, P.; Medlín, R.; Netrvalová, M.; Novák, P. Optical properties of zinc titanate perovskite prepared by reactive RF sputtering. J. Electr. Eng. 2017, 68, 10-16. [CrossRef]

19. Benito, N.; Palacio, C. Mixed Ti-O-Si oxide films formation by oxidation of titanium-silicon interfaces. Appl. Surf. Sci. 2014, 301, 436-441. [CrossRef]

20. Benito, N.; Recio-Sánchez, G.; Escobar-Galindo, R.; Palacio, C. Formation of antireflection Zn/ZnO core-shell nano-pyramidal arrays by $\mathrm{O}_{2}{ }^{+}$ion bombardment of $\mathrm{Zn}$ surfaces. Nanoscale 2017, 9, 14201-14207. [CrossRef]

21. Barr, T.L. Recent advances in X-ray photoelectron spectroscopy studies of oxides. J. Vac. Sci. Technol. A Vac. Surf. Films 1991, 9, 1793-1805. [CrossRef]

22. Zhong, I.Z.Y.; Zhang, T. Microstructure and optoelectronic properties of titanium-doped ZnO thin films prepared by magnetron sputtering. Mater. Lett. 2013, 96, 237-239. [CrossRef]

23. Sánchez, O.; Vergara, L.; Climent-Font, A.; de Melo, O.; Sanz, R.; Hernández-Vélez, M. Continuous and Nanostructured $\mathrm{TiO}_{2}$ Film Grown by DC sputtering magnetron. J. Nanosci. Nanotechnol. 2012, 12, 9148-9155. [CrossRef]

24. Liu, J.; Ma, S.Y.; Huang, X.L.; Ma, L.G.; Li, F.M.; Yang, F.C.; Zhao, Q.; Zhang, X.L. Effects of Ti-doped concentration on the microstructures and optical properties of $\mathrm{ZnO}$ thin films. Superlattices Microstruct. 2012, 52, 765-773. [CrossRef]

25. Ma, L.; Ai, X.; Huang, X.; Ma, S. Effects of the substrate and oxygen partial pressure on the microstructures and optical properties of Ti-doped ZnO thin films. Superlattices Microstruct. 2011, 50, 703-712. [CrossRef]

26. Cho, S.; Ma, J.; Kim, Y.; Sun, Y.; Wong, G.K.L.; Ketterson, J.B. Photoluminescence and ultraviolet lasing of polycrystalline $\mathrm{ZnO}$ thin films prepared by the oxidation of the metallic Zn. Appl. Phys. Lett. 1999, 75, 2761-2763. [CrossRef] 
27. Song, C.F.; Hong, T.Q.; Yuan, F.; Li, X.Y. Enhanced green emission in ZnO/zinc titanate composite materials. Mater. Sci. Eng. B 2010, 175, 243-247. [CrossRef]

28. Chaves, A.C.; Lima, S.J.; Araújo, R.C.; Maurera, M.A.; Longo, E.; Pizanid, P.S.; Simoes, L.G.P.; Soledade, L.E.B.; Souza, A.G.; dos Santos, I.M.G. Photoluminescence in disordered $\mathrm{Zn}_{2} \mathrm{TiO}_{4}$. J. Solid State Chem. 2006, 179, 985-992. [CrossRef] 